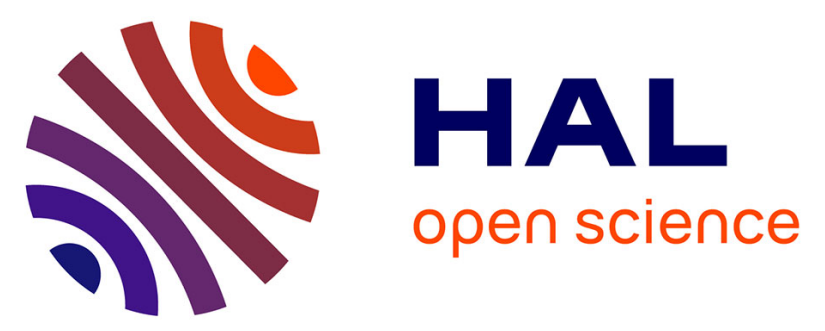

\title{
Comparison of clinical and electrophysiological features of patients with hereditary neuropathy with liability to pressure palsies with or without pain
}

Sophie Lefour, Gaël Gallouedec, Laurent Magy

\section{To cite this version:}

Sophie Lefour, Gaël Gallouedec, Laurent Magy. Comparison of clinical and electrophysiological features of patients with hereditary neuropathy with liability to pressure palsies with or without pain. Journal of the Neurological Sciences, 2020, 409, pp.116629 -. 10.1016/j.jns.2019.116629 . hal03488474

\author{
HAL Id: hal-03488474 \\ https://hal.science/hal-03488474
}

Submitted on 21 Dec 2021

HAL is a multi-disciplinary open access archive for the deposit and dissemination of scientific research documents, whether they are published or not. The documents may come from teaching and research institutions in France or abroad, or from public or private research centers.
L'archive ouverte pluridisciplinaire HAL, est destinée au dépôt et à la diffusion de documents scientifiques de niveau recherche, publiés ou non, émanant des établissements d'enseignement et de recherche français ou étrangers, des laboratoires publics ou privés.

\section{다)(1) $\$$}

Distributed under a Creative Commons Attribution - NonCommerciall 4.0 International 


\section{Comparison of clinical and electrophysiological features of patients with Hereditary Neuropathy with liability to Pressure Palsies with or without pain}

Sophie LEFOUR (1), Gaël GALLOUEDEC, MD (2), Laurent MAGY, MD, PhD (3)

(1) Department of Neurology, University Hospital Centre of Reims

45 rue Cognacg Jay, 51100 Reims, France

Email address: sophie.lefour@wanadoo.fr

(2) Department of Neurophysiology, University Hospital Centre of Limoges

2 Avenue Martin Luther King, 8700 Limoges, France

Email address: gael.gallouedec@chu-limoges.fr

(3) Department of Neurology, University Hospital Centre of Limoges

2 Avenue Martin Luther King, 8700 Limoges, France

Email address: laurent.magy@unilim.fr

- Corresponding author. Miss LEFOUR Sophie, e-mail: sophie.lefour@wanadoo.fr,

Phone number: (+33) 06.39.45.97.23 and postal address: 45 rue Cognacq Jay, 51100 REIMS, France

- Keywords: hereditary neuropathy with liability to pressure palsies; neuropathic pain; polyneuropathy; electrophysiology; PMP22, small fibres.

- Words number: 2496 (title, abstract (249 words) and legends included)

- Ethics Comitee number : 280-2018-46

- Authors have no conflict of interest to disclosure 


\section{ABSTRACT}

Background: Hereditary neuropathy with liability to pressure palsies (HNPP) is a rare neuropathy with a heterogeneous clinical profile. Painless recurrent palsies are the usual presentation, but neuropathic pain could be predominant or inaugural. Browsing the medical literature, we only found two articles reffering to this important clinical feature. Whether there are differences between patients with or without pain is unclear. The main objective of this study was to compare the clinical and electrophysiological features of these patients and to evaluate the impact on their disability.

Methods: All patients diagnosed with HNPP at the Limoges University Hospital Centre were included and separated into two groups according to the presence or absence of neuropathic pain. In each case, the clinical, genetic, electrodiagnostic, therapeutic features and the modified Rankin Scale (mRS) were evaluated.

Results: Out of 23 patients, 52\% presented with neuropathic pain. There was no difference between groups regarding to clinical and electrophysiological features, except for the amplitude of the ulnar sensory nerve $(p<0,003)$. The amplitudes of sensory nerve action potentials (SNAPs) seemed to be higher in patients with pain, but were below the lower limit of normal. Patients with pain had a higher mRS than patients without pain $(p<0,007)$.

Conclusion: This study supports previous published results and highlights a trend for higher sensory amplitudes in HNPP patients with pain. We found a prevalence of neuropathic pain of $52 \%$ in patients with HNPP, underlining the need to systematically assess pain in such patients in order to improve their management. 


\section{INTRODUCTION}

Hereditary Neuropathy with liability to Pressure Palsies (HNPP) is a rare autosomal dominant disorder. In $84 \%$ of cases, a gene deletion on chromosome 17, coding for the PMP22 protein of myelin sheath is responsible (1-3). HNPP prevalence is estimated between 2 to 16 per 100000 cases according to studies, but the disease is underdiagnosed because of nonspecific symptoms and lack of family history in many cases $(4,5)$.

The electrodiagnostic features of HNPP are a slowing down of nerve conduction, an increase in distal motor latency (DML) or conduction blocks (CB), all features being especially prominent at entrapment sites. A moderate reduction of the sensory nerve action potential (SNAP) amplitudes is also frequent. However, there is no absolute criteria to diagnose HNPP by electrodiagnostic studies alone (4,6-10).

Clinical presentation of HNPP is classically represented by the recurrence of painless, unique or multiple sensory or motor deficit in a nerve trunk distribution at entrapment sites. Root or plexus involvement is also possible. Precipitating factors are related to positions such as crossing legs or immobility during a general anaesthesia. In some cases, the main presentation is similar to a polyneuropathy, which makes diagnosis even more challenging (11). Initial presentations with pain have been described, sometimes without nerve palsy $(2,12)$. Pain in HNPP is an emerging concept, in both short and long-term. Regarding recent cohorts, 15 to $75 \%$ of HNPP patients suffer from chronic neuropathic pain (12-14). These patients may be erroneously considered as suffering from fibromyalgia. In the literature, relation between pain and disability has never been evaluated, but the concerns about quality of life appear important for a personal and tailored management.

Recently, Yilmaz et al. have tried to highlight electrophysiological differences between patients presenting HNPP with and without neuropathic pain (13). A higher amplitude in sural SNAP was observed in patients suffering from pain, but the difference was not significant in this small cohort.

The main objective of the present study was to compare clinical and electrophysiological features of patients with HNPP with or without neuropathic pain. The 
secondary objective was to determine the impact on disability and pain killer consumption on these patients.

\section{PATIENTS AND METHODS}

The demographic, clinical and electrodiagnostic characteristics of 23 patients genetically diagnosed with HNPP over a period of twenty years in the University Hospital of Limoges were retrospectively analysed. In all cases, data about age and type of first symptom, age at molecular diagnosis, family history, presence of pes cavus or neuropathic pain, modified Rankin Scale (mRS) and analgesic use were recorded. Patients also affected by other potential causes of neuropathy, such as diabetes, chronic alcoholism, neurotoxic treatments were excluded. Each patient was affected in a pain or pain free group depending on whether neuropathic pain was present at the first neurological evaluation. Rheumatic or mechanical pain were not taken into account for patients' classification.

From a clinical point of view, distal paraesthesia referred to length-dependant numbness and tingling. Neuropathic pain symptoms referred to burning, painful cold, hyperesthesia or electric discharge. Transient palsy consisted in sensorimotor or motor deficit in a root or nerve trunk distribution.

We considered the first electrodiagnostic study as a reference for all patients. Distal motor latencies (DML), distal amplitudes of compound muscle action potentials (CMAPs), motor nerve conduction velocities (MNCVs), presence of $\mathrm{CB}$ or temporal dispersion (TD) in several nerves were evaluated. CB was defined as a $30 \%$ reduction of amplitude of CMAPs from a distal to proximal stimulation. On the tibial nerve, a decrease of $50 \%$ was retained. Slowing down of conduction velocity at entrapment sites was considered significant above 10 $\mathrm{m} / \mathrm{s}$ compared to the conduction velocity outside entrapment sites. TD was defined as a $30 \%$ increase of duration CMAPs. Antidromic method was used for sural and radial sensory conduction velocities (SCV), whereas median and ulnar SCV were obtained by the orthodromic method. 
The non-parametric Mann Whitney test was used to compare electrophysiological features between HNPP patients suffering neuropathic pain and pain free patients. The difference was significant for $p<0,05$. Correlation between neuropathic pain and mRS was also studied by the Mann Whitney test.

\section{RESULTS}

There were 23 patients (14 women), 22 of whom had the classical 17p11.2 deletion. The last one had a heterozygous pathogenic variant in the PMP22 gene sequence (c.98G>A). Genetic analysis was requested in the following cases: positional sensory symptoms, motor root or trunk nerve palsy, slowing of MNCV or CB in entrapment sites, or a positive family history.

Demographic and clinical characteristics are presented in table 1. In our 23 patients, the mean delay between first symptoms and molecular diagnosis was 7 years. The age at first clinical manifestation extended from 4 to 68 years. Pain was present in twelve patients (52\%). Among them, ten had burning of lower limbs and the others experienced more diffuse neuropathic pain. Pain was the first symptom in two patients: a 54-year-old woman, misdiagnosed with fibromyalgia for seven years and a 54-year-old man who suffered from pain and burning in the legs with a history of carpal tunnel surgery. At the onset of the disease, the radial nerve was more frequently affected, but two cases of post-operative femoral palsies were also observed. 
Table 1. Demographic and clinical characteristics of 23 patients with HNPP

\begin{tabular}{|c|c|}
\hline \multicolumn{2}{|l|}{ Gender n (\%) } \\
\hline women & $14(61)$ \\
\hline men & $9(38)$ \\
\hline Age at diagnosis mean [range] & 54 [4-75] \\
\hline Age at first symptom mean [range] & $47[4-68]$ \\
\hline Family history $\mathrm{n}(\%)$ & $10(43)$ \\
\hline Neuropathic pain $\mathrm{n}(\%)$ & $12(52)$ \\
\hline \multicolumn{2}{|l|}{ Absence of reflexes $n(\%)(N=18)$} \\
\hline ankle jerks & $4(22)$ \\
\hline lower limbs & $5(28)$ \\
\hline generalized & $3(16)$ \\
\hline \multicolumn{2}{|l|}{ Clinical phenotype $\mathrm{n}(\%)$} \\
\hline polyneuropathy & $7(30)$ \\
\hline single mononeuropathy & $3(13)$ \\
\hline multiple mononeuropathy & $11(48)$ \\
\hline neuropathic pain & $2(9)$ \\
\hline Pes cavus $\mathrm{n}(\%)$ & $8(35)$ \\
\hline \multicolumn{2}{|l|}{ modified Rankin Scale $\mathrm{n}(\%)$} \\
\hline 0 & $13(57)$ \\
\hline 1 & $2(9)$ \\
\hline 2 & $3(13)$ \\
\hline 3 & $2(9)$ \\
\hline 4 & $3(13)$ \\
\hline 5 & $0(0)$ \\
\hline \multicolumn{2}{|l|}{ First neurological event $\mathbf{n}(\%)$} \\
\hline distal paresthesia & $8(35)$ \\
\hline positional paresthesia & $3(12)$ \\
\hline ulnar & $1(4)$ \\
\hline median & $1(4)$ \\
\hline fibular & $1(4)$ \\
\hline transient palsy & $10(44)$ \\
\hline radial & $5(22)$ \\
\hline ulnar & 2(9) \\
\hline femoral & $2(9)$ \\
\hline supra-scapular & $1(4)$ \\
\hline neuropathic pain & $2(9)$ \\
\hline
\end{tabular}

Nerve conduction studies were available in only 14 patients. All patients had one or more $\mathrm{CB}$ and/or MNCV slowing. Conduction block was present within 10 patients (71\%): in the median nerve at the forearm (6/24 nerves), the ulnar nerve across the elbow (6/24 nerves), the tibial nerve (6/17 nerves) and the fibular nerve across the fibular head $(8 / 21$ 
nerves). The other four cases presented prolonged DMLs and diffused slowing and prolonged $F$ wave latencies. Electrodiagnostic features of carpal tunnel syndrome were present in 9 patients $(64 \%)$, bilaterally for 7 of them. Median SNAP was not obtained in 4 cases and sural SNAP in one.

Electrophysiological comparison of patients with or without pain is presented in table 2. There were no differences between the two groups in terms of gender and mean age of first symptoms (47 and 36 years respectively). Electrodiagnostic data were similar for $\mathrm{CB}$, temporal dispersion and motor conduction in both groups. All patients had abnormalities of sensory nerve conduction. In the pain free group, amplitudes of SNAPs were significantly lower for the ulnar nerve only $(p<0,002)$. 
Table 2. Clinical and electrophysiologic comparisons of HNPP patients with or without pain

\begin{tabular}{|c|c|c|c|}
\hline & $\begin{array}{l}\text { HNPP with pain } \\
\qquad N=9\end{array}$ & $\begin{array}{c}\text { pain free HNPP } \\
\qquad N=5\end{array}$ & p-value \\
\hline Conduction Block n (\%) & $19 / 57(33)$ & $6 / 29(21)$ & NS \\
\hline Temporal Dispersion $\mathrm{n}(\%)$ & $3 / 34(8)$ & $2 / 16(13)$ & NS \\
\hline \multicolumn{4}{|c|}{ CMAP amplitudes (mV) (mean, range) } \\
\hline median & $5,5[1-15,8]$ & $5,5[2,2-13,3]$ & NS \\
\hline ulnar & $6,9[2,8-10,9]$ & $9,4[4-13,7)$ & NS \\
\hline fibular & $2,6[0-6,1]$ & $2,1[0,5-6,1]$ & NS \\
\hline tibial & $4,5[0,4-14]$ & $5,4[1,7-8,2]$ & NS \\
\hline \multicolumn{4}{|l|}{ DML (m/s) (mean, range) } \\
\hline median & $5,3[3,7-13,1]$ & $5,4[3,3-9,8]$ & NS \\
\hline ulnar & $2,7[2,3-6,1]$ & $3,3[3-4,3]$ & NS \\
\hline fibular & $4,8[3,2-16,3]$ & $7[5,1-10]$ & NS \\
\hline tibial & $4,9[2,2-6,7]$ & $5,8[4-7,5]$ & NS \\
\hline \multicolumn{4}{|l|}{ MNCV (m/s) (mean, range) } \\
\hline median & $49,7[21,7-60]$ & $47[40,8-54]$ & NS \\
\hline distal ulnar & $51,1[27,1-71,9]$ & $50,6[43,8-57,4]$ & NS \\
\hline proximal ulnar & $35[5,1-67,7]$ & $36,1[26,9-48,6]$ & NS \\
\hline distal fibular & $41,4[30,6-50,8]$ & $39,4[32,7-45,2]$ & NS \\
\hline proximal fibular & $39,3[32,6-54,6]$ & $31,1[30,6-47,6]$ & NS \\
\hline tibial & $43,2[32-71,4]$ & $37,3[32-68]$ & NS \\
\hline \multicolumn{4}{|c|}{ SNAP amplitudes $(\mu \mathrm{V})$ (mean, range) } \\
\hline index median & $8,7[0-33,7]$ & $10,1[0-14,2]$ & NS \\
\hline fifth finger ulnar & $8,4[2,6-38,2]$ & $2[1,5-4,5]$ & $<0,002$ \\
\hline radial & $20[4,9-42,2]$ & $11,1[1,3-18,5]$ & NS \\
\hline sural & $4,7[0-17,5]$ & $4,8[1,4-8,6]$ & NS \\
\hline \multicolumn{4}{|l|}{ SNCV (m/s) (mean, range) } \\
\hline index median & $35[19,8-51,6]$ & $35,5[23,6-40,9]$ & NS \\
\hline fifth finger ulnar & $35,8[23,7-52,4]$ & $36,5[24,9-40,4]$ & NS \\
\hline radial & $52,6[44,3-61,5]$ & $35,2[26-49,3]$ & $<0,005$ \\
\hline sural & $31,7[21,2-45]$ & $33,8[28-36,5]$ & NS \\
\hline
\end{tabular}

CMAP: compound muscle action potential; DML: distal motor latency; MNCV: motor nerve conduction velocity; NS: non significant; SNCV: sensory nerve conduction velocity. 
Data on treatments were available for fifteen patients only. In the course of their disease, 7 of them had never used analgesics (figure 1). Two patients had been treated with up to 5 different pain killers because of diffuse painful polyneuropathy with burning and electric discharges. The medications used were amitriptyline, hexaquin, gabapentin, pregabalin and lidocaine patch for one and pregabalin, paracetamol, ibuprofen, tramadol and transcutaneous electrical nerve stimulation for the other.

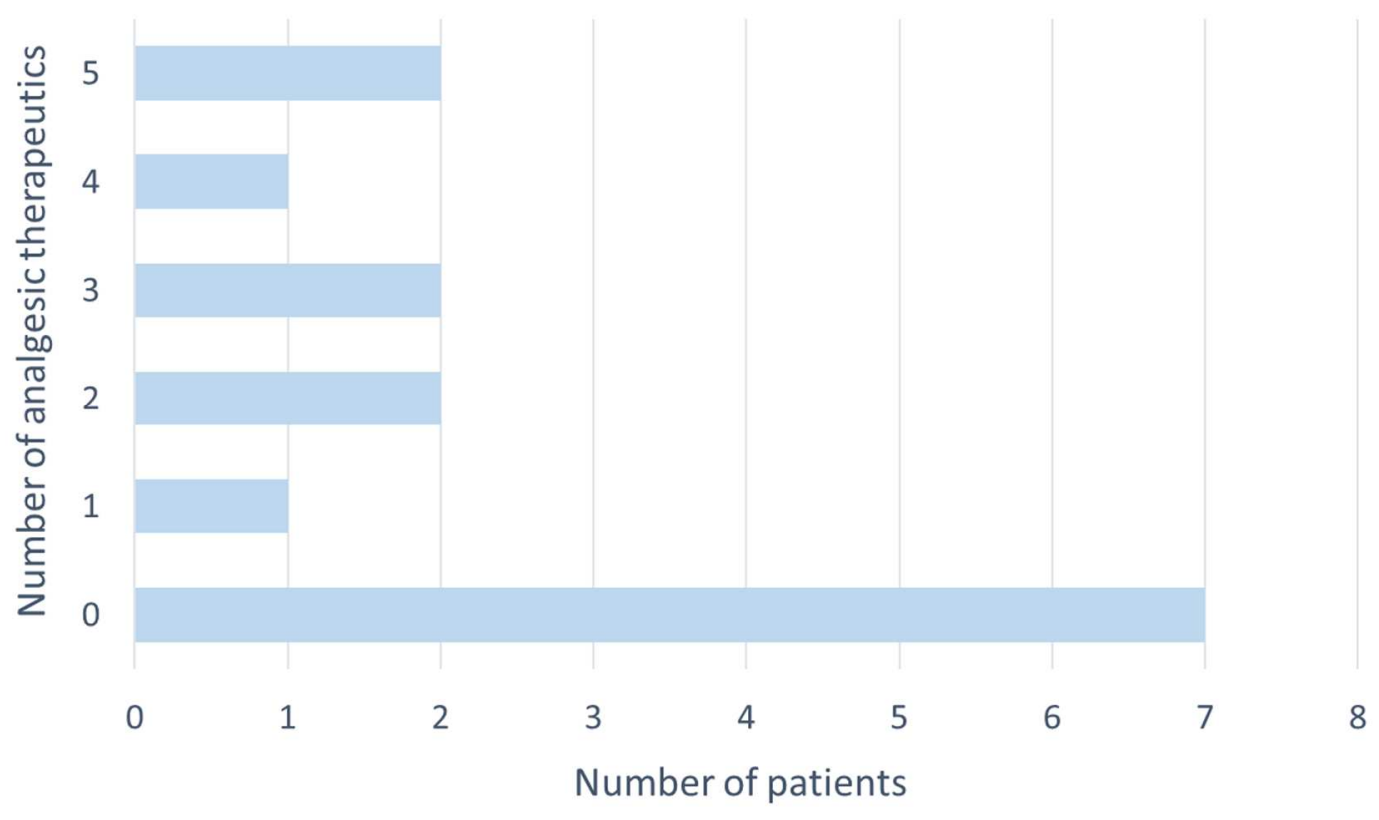

Figure 1. Histogram of pain killer consumption in HNPP patients $(n=15)$

Among the 23 patients, $13(57 \%)$ had no notable disability ( $m R S=0)$, whereas use of canes was necessary for 3 of them (mRS>4) (table 1). Figure 2 shows mRS repartition according to the presence/absence of neuropathic pain. Most elevated scores concerned preferentially patients with pain $(p=0,007)$. The mean mRS was 2 (range [0-4]) in the HNPP group with pain and was 0 (range [0-4]) in the pain free group. 


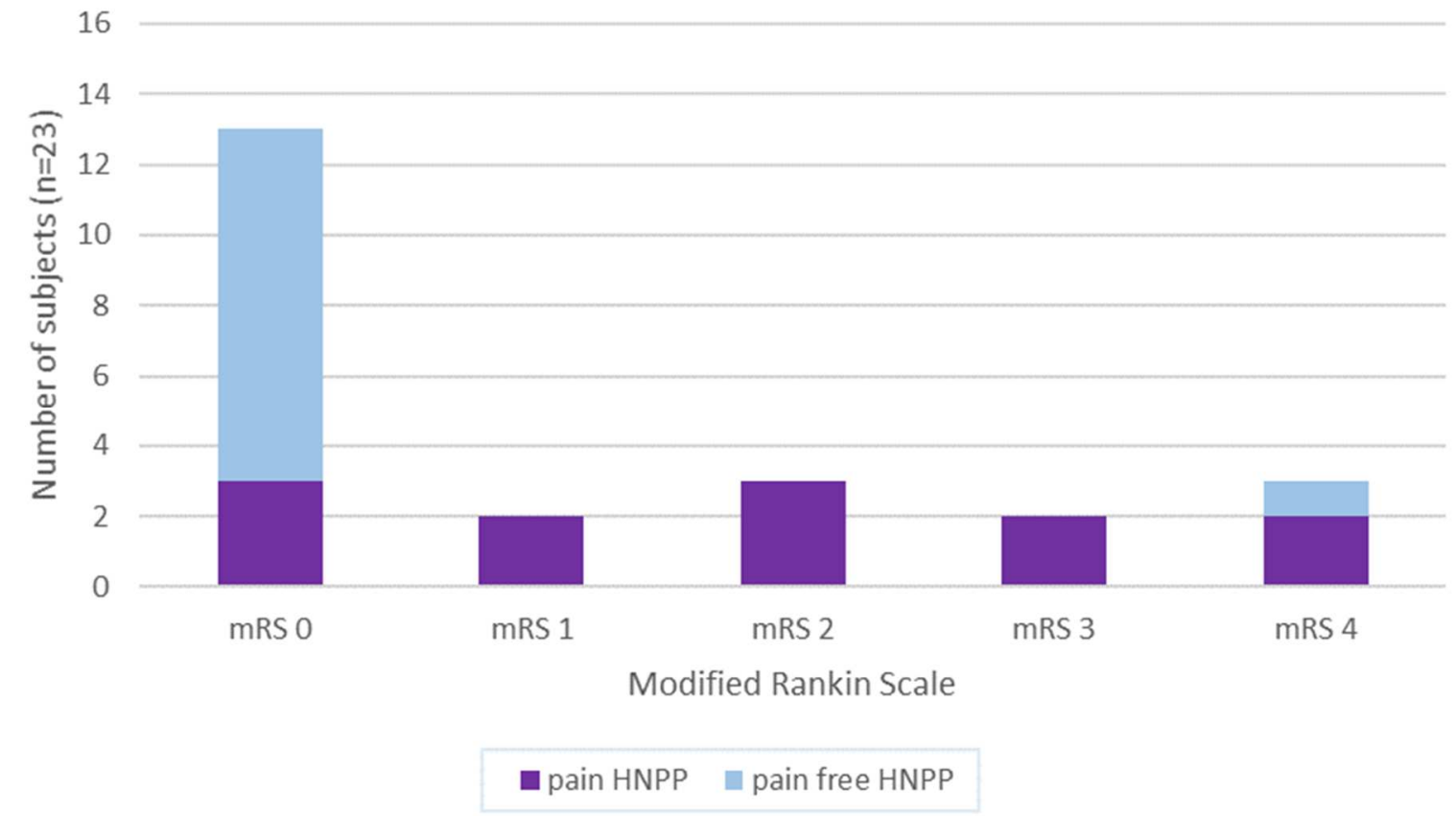

Figure 2. Repartition of patients with or without pain according to the modified Rankin Scale

\section{DISCUSSION}

Demographic and clinical features of our patients concord with the literature. In our cohort of patients who were diagnosed with HNPP, 61\% presented with the classical phenotype of HNPP with transient recurrent palsies. The remaining patients had polyneuropathy phenotype (30\%) or isolated neuropathic pain (9\%). These results support the observation of Pareyson et al. who suggested that HNPP can be diagnosed in cases of non-specific sensory symptoms, without a history of positional palsy (11). As already mentioned, a family history of neuropathy or pes cavus is often absent ( $57 \%$ and $65 \%$ respectively) in HNPP. This underlines the interest of questioning and examining family members and the necessity of performing nerve conduction studies to search for abnormalities usually encountered in HNPP.

Electrodiagnostic features proposed by several authors were present in our patients, reinforcing the external validity of the present study $(4,9)$. Absence of CB was observed in $29 \%$ of cases $(25 / 86$ nerves). Other studies report similar rates $(8,11,12)$. Then, absence of CB should not be an exclusion criterion for HNPP diagnosis. In tibial nerves, CB were 
considered significant above $50 \%$, but we cannot guarantee that stimulation was supramaximal for each case and conduction block could be over-estimated.

In our study, half of the patients with HNPP suffered from neuropathic pain (52\%), mainly burning in the lower limbs. In other cohorts of similar size, the pain rate varied between $16.6 \%$ and $74 \%$ of patients $(13,14)$. There were no electrophysiological differences based on the presence/absence of pain in these series. By contrast, we found higher amplitudes in some sensory nerves in patients with pain, but this is only significant for the ulnar nerve. The Yilmaz et al. study had already reported sural SNAP preservation in painfull HNPP (13). The main explanation could be the small number of patients in these studies and the difficulties to standardize electrodiagnostic studies.

Even if involvement of sensory nerves can explain neuropathic pain in HNPP, some patients had normal sensory amplitudes. The pathophysiological mechanism underlying this result remains unknown, but the hypothesis of an involvement of small fibres should be raised. Indeed, no systematic morphological study on skin biopsies in HNPP has been conducted so far to support this hypothesis. Nevertheless, Duchesne et al. showed small fibre involvement by skin biopsy in patients with CMT1A (15).

The impact of pain on the quality of life in patients with HNPP hasn't been extensively discussed previously, but it seems to be an important factor to consider in the management of these patients. In our study, the highest levels of modified Rankin Scale are significantly correlated with the presence of pain, mainly in the lower limbs, forcing patients to overuse pain killers. In the study of Beales et al., $66 \%$ of people who experienced neuropathic pain were unable to work because of their symptoms (14). The Brief Pain Inventory Pain Interference Scale (BPI-PIS) was used to assess the effects of pain on function. General activity, mood, walking ability, normal work, relationships with others, sleep and enjoyment of life were significantly lower in participants who experienced pain.

Our study has some limitations, such as the small size of the cohort and its retrospective nature. Some nerve conduction findings and clinical data were not available, which makes extrapolation of our results difficult. Moreover, pain was not evaluated 
objectively by the scales used in neuropathies, such as the neuropathic pain symptom inventory for example (16). However, our study supports previous results on electrophysiological profiles of HNPP patients with and without pain. Moreover, we highlight the impact of pain on disability in patients with HNPP and neuropathic pain. We show a trend towards SNAP preservation in patients with pain compared to others. We think the screening of neuropathic pain in patients with HNPP is important as well because it may impact disability and ultimately quality of life. Larger prospective multicentric studies should be conducted, in order to confirm our results and to precise the potential disabling impact of pain in HNPP. 


\section{REFERENCES}

1. Koehler PJ. Hereditary neuropathy with liability to pressure palsies: the first publication (1947). Neurology. 2003 Apr 8;60(7):1211-3.

2. Yurrebaso I, Casado OL, Barcena J, Perez de Nanclares G, Aguirre U. Clinical, electrophysiological and magnetic resonance findings in a family with hereditary neuropathy with liability to pressure palsies caused by a novel PMP22 mutation. Neuromuscul Disord NMD. 2014 Jan;24(1):56-62.

3. Murakami T, Garcia CA, Reiter LT, Lupski JR. Charcot-Marie-Tooth disease and related inherited neuropathies. Medicine (Baltimore). 1996 Sep;75(5):233-50.

4. Luigetti M, Del Grande A, Conte A, Lo Monaco M, Bisogni G, Romano A, et al. Clinical, neurophysiological and pathological findings of HNPP patients with 17p12 deletion: a single-centre experience. J Neurol Sci. 2014 Jun 15;341(1-2):46-50.

5. Chen B, Niu S, Wang X, Li W, Chen N, Zhang Z. Clinical, electrophysiological, genetic, and imaging features of six Chinese Han patients with hereditary neuropathy with liability to pressure palsies (HNPP). J Clin Neurosci Off J Neurosurg Soc Australas. 2018 Feb;48:133-7.

6. Verhagen WI, Gabreëls-Festen AA, van Wensen PJ, Joosten EM, Vingerhoets HM, Gabreëls FJ, et al. Hereditary neuropathy with liability to pressure palsies: a clinical, electroneurophysiological and morphological study. J Neurol Sci. 1993 Jun;116(2):17684.

7. Mouton P, Tardieu S, Gouider R, Birouk N, Maisonobe T, Dubourg O, et al. Spectrum of clinical and electrophysiologic features in HNPP patients with the 17p11.2 deletion. Neurology. 1999 Apr 22;52(7):1440-6.

8. Gouider R, LeGuern E, Gugenheim M, Tardieu S, Maisonobe T, Léger JM, et al. Clinical, electrophysiologic, and molecular correlations in 13 families with hereditary neuropathy with liability to pressure palsies and a chromosome 17p11.2 deletion. Neurology. 1995 Nov;45(11):2018-23.

9. Dubourg O, Mouton P, Brice A, LeGuern E, Bouche P. Guidelines for diagnosis of hereditary neuropathy with liability to pressure palsies. Neuromuscul Disord NMD. 2000 Mar;10(3):206-8.

10. Robert-Varvat F, Jousserand G, Bouhour F, Vial C, Cintas P, Echaniz-Laguna A, et al. Hereditary neuropathy with liability to pressure palsy in patients under 30 years old: Neurophysiological data and proposed electrodiagnostic criteria. Muscle Nerve. 2018 Feb;57(2):217-21.

11. Pareyson D, Scaioli V, Taroni F, Botti S, Lorenzetti D, Solari A, et al. Phenotypic heterogeneity in hereditary neuropathy with liability to pressure palsies associated with chromosome 17p11.2-12 deletion. Neurology. 1996 Apr;46(4):1133-7.

12. de Oliveira APM, Pereira RC, Onofre PT, Marques VD, de Andrade GB, Barreira AA, et al. Clinical and neurophysiological features of the hereditary neuropathy with liability to pressure palsy due to the 17p11.2 deletion. Arq Neuropsiquiatr. 2016 Feb;74(2):99105. 
13. Yilmaz U, Bird TT, Carter GT, Wang LH, Weiss MD. Pain in hereditary neuropathy with liability to pressure palsy: an association with fibromyalgia syndrome? Muscle Nerve. 2015 Mar;51(3):385-90.

14. Beales D, Fary R, Little C, Nambiar S, Sveinall H, Yee YL, et al. Characterisation of pain in people with hereditary neuropathy with liability to pressure palsy. J Neurol. 2017 Dec;264(12):2464-71.

15. Duchesne M, Danigo A, Richard L, Vallat J-M, Attarian S, Gonnaud P-M, et al. Skin Biopsy Findings in Patients With CMT1A: Baseline Data From the CLN-PXT3003-01 Study Provide New Insights Into the Pathophysiology of the Disorder. J Neuropathol Exp Neurol. 2018 Apr 1;77(4):274-81.

16. Bouhassira D, Attal N, Fermanian J, Alchaar H, Gautron M, Masquelier E, et al. Development and validation of the Neuropathic Pain Symptom Inventory. Pain. 2004 Apr;108(3):248-57.

\section{Acknowledgements}

none 